\title{
Cavity Problems Following Canal Wall Down Mastoidectomy in Chronic Suppurative Otitis Media: Are We Treating Adequately or Making Them Regular Outpatients?
}

\author{
Supriya M Bhat ${ }^{1}$, Rakesh Vuppala ${ }^{2}$
}

\begin{abstract}
Aim: To identify and address the postoperative cavity problems following canal wall down mastoidectomy (CWDM) early in chronic suppurative otitis media (CSOM) to minimize the persistent otological problems was the aim of the study.

Materials and methods: This was a prospective, observational study to describe the postoperative cavity problems following CWDM in CSOM patients. Results: Of 50 patients, men (54\%) outnumbered women. The patients were aged between 6.5 years and 50 years with a mean \pm standard deviation of $21.19 \pm 10.58$ years. Unilateral involvement was frequent ( $82 \%)$. Otorrhea (100\%), hearing loss ( $86 \%$ ), and perforation of tympanic membrane (84\%) were the major findings. The mean duration of otorrhea and hearing loss were 7.57 years (5 days-30 months) and 1.33 years (2 days-7 years), respectively. Bilateral sclerosis (70\%) was a remarkable radiological finding. Complications were categorized as extracranial $(16 \%)$ and intracranial (20\%). Intracranial complications included meningitis (03), subdural empyema (02), cerebellar abscess (02), temporal lobe abscess (02), and cerebritis (01). Mastoid abscess (07) and facial nerve palsy (01) were the extracranial complications. Intraoperative complications included cholesteatoma and destruction of incus; The common location of cholesteatoma was the epitympanum (62\%) followed by a mastoid bowl (26\%). Destruction of the incus either part or as a whole was noted in all. Superficial infection of the cavity, transient discharge, and granulations were the common postoperative complications. Facial nerve involvement after surgery was seen in three. Ninety-eight percent of the postoperative cavities were epithelialized by 6 months. Recurrent discharges from cavity, granulations, and debris were the persistent complications.
\end{abstract}

Conclusion: We reemphasize the need for meticulous surgery (adequately lowered facial ridge, circumferential saucerization, and wide meatoplasty), as multiple factors are responsible for postsurgical cavity problems.

Keywords: Canal wall down mastoidectomy, Cavity problems, Chronic suppurative otitis media, Granulations, Persistent discharge.

Otorhinolaryngology Clinics: An International Journal (2021): 10.5005/jp-journals-10003-1361

\section{INTRODUCTION}

Chronic suppurative otitis media (CSOM) is a clinical condition, which can result in intracranial and extracranial complications, if untreated. Cholesteatoma is a frequent complication of CSOM that often needs surgical intervention, mastoidectomy being the most preferred surgery.

Surgery is the mainstay of management, i.e., eradication of the disease to produce a dry, stable, and safe ear. Maintenance or restoration of hearing is a secondary goal. Open cavity mastoidectomy aims to achieve these, in addition to creating a large enough meatus for examination, mastoid air cells, and provides a self-cleaning epithelized dry cavity and helps in maximum hearing. ${ }^{1,2}$

The management of cholesteatoma requires a prolonged, diligent postoperative follow-up due to significant rate of recidivistic disease. Canal wall down mastoidectomy (CWDM) is an effective procedure associated with less postsurgical complications ${ }^{3}$ and offers maximal benefit with better hearing. ${ }^{4}$

The advantages of this procedure include excellent intraoperative exposure of cholesteatoma facilitating eradication of the disease and easy detection of recurrence postoperatively. It decreases the need for second-stage operation and hence, is costeffective making it an optimum surgery, especially in the Indian setting.

The major drawback with CWDM is cavity problems, such as discharge from the ear, granulations, wax, keratin accumulation,

\begin{abstract}
$\overline{{ }^{1} \text { Department of ENT, Krishna Eye and ENT Hospital, Chennai, Tamil }}$ Nadu, India

${ }^{2}$ Department of Otolaryngology, Apollo Institute of Medical Sciences and Research, Hyderabad, Telangana, India

Corresponding Author: Rakesh Vuppala, Department of Otolaryngology, Apollo Institute of Medical Sciences and Research, Hyderabad, Telangana, India, e-mail: rakeshvuppala@gmail.com

How to cite this article: Bhat SM, Vuppala R. Cavity Problems Following Canal Wall Down Mastoidectomy in Chronic Suppurative Otitis Media: Are We Treating Adequately or Making Them Regular Outpatients? Int J Otorhinolaryngol Clin 2021;13(1):11-17.

Source of support: Nil

Conflict of interest: None
\end{abstract}

and difficulty in prescribing hearing aids, dizziness, and small meatus encountered postoperatively. If cavity problems and the means to prevent or alleviate them are identified, the quality of life of patients can be improved.

Persistent ear discharge after CWDM as the primary procedure makes the patient a social handicap. The proportion of persistent or intermittent ear discharge after mastoidectomy ranges from $10 \%$ to $60 \%{ }^{5-7}$ but $\sim 10 \%$ in expert hands. ${ }^{6}$

Otorrhea following open mastoid cavity surgery is common and is estimated to occur in $10 \%-35 \%$ of patients. It is usually due

( ) Jaypee Brothers Medical Publishers. 2021 Open Access This article is distributed under the terms of the Creative Commons Attribution 4.0 International License (https://creativecommons.org/licenses/by-nc/4.0/), which permits unrestricted use, distribution, and non-commercial reproduction in any medium, provided you give appropriate credit to the original author(s) and the source, provide a link to the Creative Commons license, and indicate if changes were made. The Creative Commons Public Domain Dedication waiver (http://creativecommons.org/publicdomain/zero/1.0/) applies to the data made available in this article, unless otherwise stated. 
to failure of epithelialization of the mastoid cavity for a variety of reasons. Even in an ideal cavity, which is small with a low facial ridge and a large meatus, there is $10 \%$ discharge recurrently. ${ }^{8}$

CWDM will no doubt cure the disease in most of the cases but in the process, the patient is left with a large postoperative cavity, which may be associated with many issues, such as retention of wax, debris, and discharge.

The management of failed CWDM requires a meticulous approach for disease control. The most important factors that promote persistent disease are an inadequately lowered facial ridge, a stenotic meatus, a bony overhang of cavity edges, and a prominent mastoid tip. Restoration of hearing in the revision procedures, though desirable, is of secondary importance.

Hence, we attempted to identify various problems related to the mastoid cavity in patients who underwent modified radical or radical mastoidectomy as their primary procedure.

\section{Materials and Methods}

This prospective study was conducted by the Department of Ear, Nose and Throat of a tertiary care referral hospital after review and approval by the institutional ethics committee. Written informed consent was taken from all the adult patients and the parents of pediatric patients, prior to screening.

Patients who underwent CWDM were included and those who underwent canal wall up mastoidectomy (CWUM) were excluded.

Included patients were studied as per the proforma; detailed history was taken; clinical examination, including a detailed examination of the ear, paranasal sinuses, oral cavity, and pharynx, was performed. Possibility of any focus of infection and systemic diseases unrelated to the ear disease were ruled out.

Otoscopic, otomicroscopic examination, and tuning fork tests were performed. Blood investigations, such as hemoglobin, total and differential leukocytes count, bleeding and clotting times, and urine examination (albumin, sugar, and microscopic examination), were performed. Swabs from ear discharge were subjected to culture and sensitivity.

All patients underwent modified radical mastoidectomy through a postaural approach. Temporalis fascia graft was used for all (Fig. 1). After lowering the posterior canal wall, the tympanic cavity and the mastoid cavity were merged into a single round cavity. The lateral

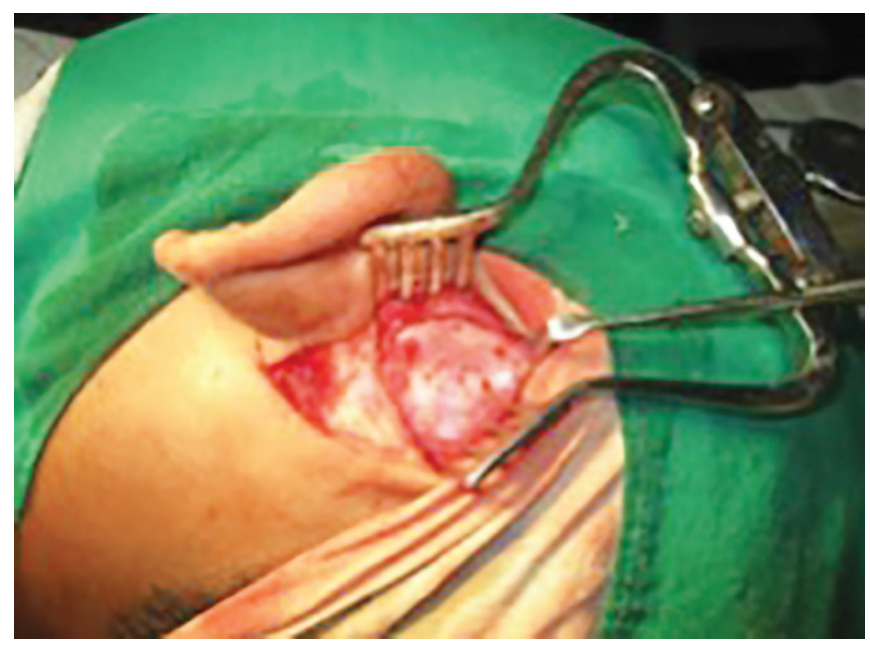

Fig. 1: Postaural William Wilde's incision and harvesting of temporalis fascia graft margins of the cavity were smoothened out (Fig. 2) as uneven surface, sharp ridges and pockets in cavities will cause accumulation of crust or debris that slows down the epithelial migration, thereby delaying the healing of the cavity. Reconstruction of hearing mechanism was undertaken in possible cases. Wide and adequate meatoplasty (Fig. 3) was done for all included patients.

Following surgery, cavity and the external auditory canal were filled with gel foam, a mastoid compression bandage was applied, which was replaced on the second postoperative day and finally taken off on the 7th postoperative day along with suture removal. Postoperative intravenous antibiotics were given for the first 7 days during their stay in the hospital and oral antibiotics were continued for another 7 days. All were followed up weekly for 1 month, fortnightly for 3 months and then once in 2 or 3 months for a minimum period of 6 months. The healing time of the postoperative cavity was noted in all. During every follow-up, all were evaluated for the persistence of discharge, collection of debris, or any other complications.

\section{Statistical Analysis}

Assessment parameters were defined as per the protocol and captured on the predefined, preapproved pro forma. Data were collected using the Microsoft Excel sheet (2007) and analyzed.

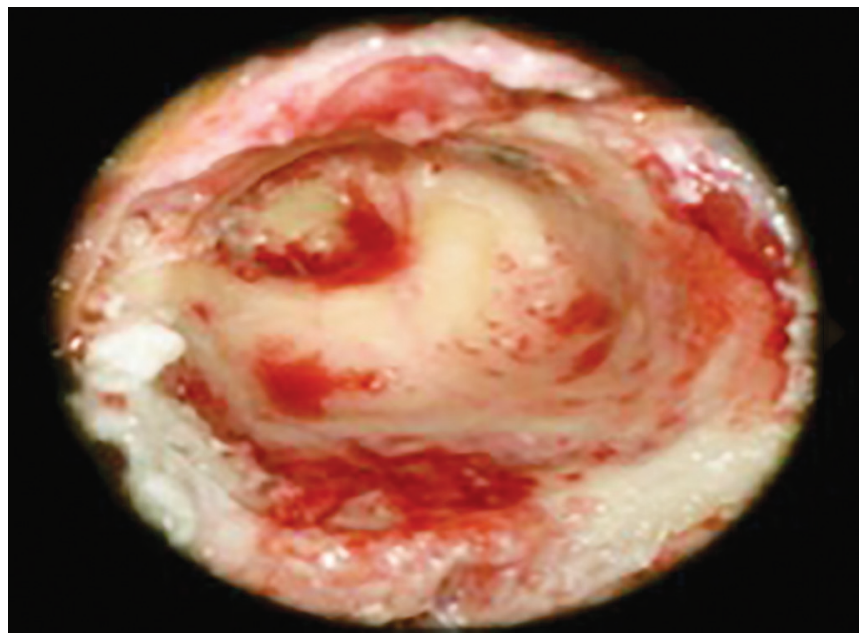

Fig. 2: Saucerized mastoid cavity

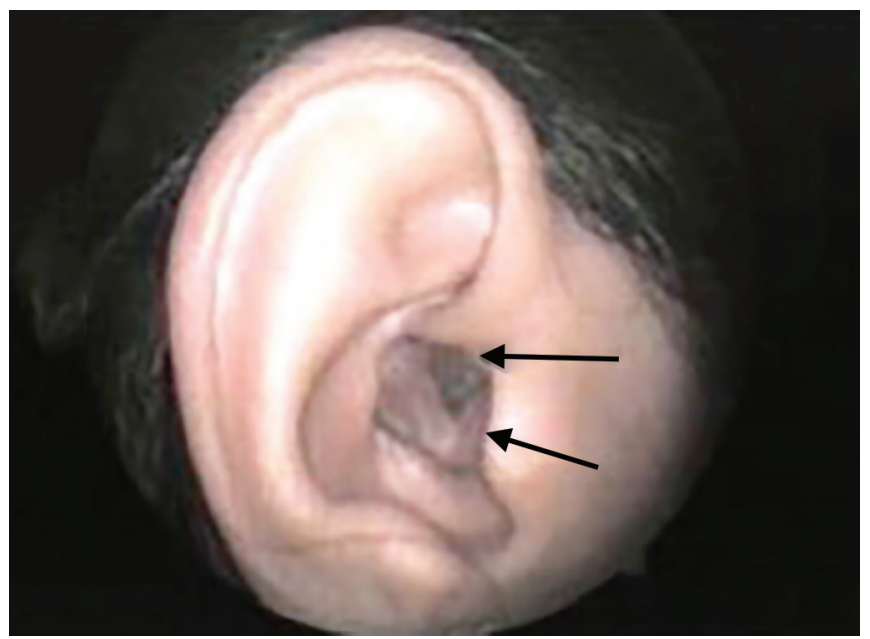

Fig. 3: Adequate meatoplasty 
Results were expressed as frequency, mean \pm standard deviation (SD), percentage, and range. Pictorial representations and tabulation were given as appropriate.

\section{Results}

Fifty patients satisfying the inclusion and exclusion criteria were included. Men ( $n=27,54 \%)$ outnumbered women ( $n=23,46 \%)$ with a ratio of 1.173:1. The age of patients ranged from 6.5 years to 50 years with a mean \pm SD of $21.19 \pm 10.58$ years. Patients aged 11 to 20 years comprised $46 \%$ of the study population (Table 1 ).

Of 50 patients, nine (1\%) and 41 (82\%) had bilateral and unilateral CSOM, respectively. Among those with unilateral disease, 22 (44\%) had discharge from the right ear while 19 (38\%) had from the left.

All patients presented with otorrhea; 43 (86\%) complained of hearing loss. The mean duration of otorrhea was 7.57 years (range 5 days -30 months) while that of hearing loss was 1.33 years (range 2 days -7 years) (Table 2 ).

The frequency of the clinical signs observed, namely site of perforation, presence of aural polyp and postaural swelling, was recorded (Figs 4 to 7 ). Tympanic membrane perforation was noted in $42(84.0 \%)$ patients (Table 3$)$.

$\mathrm{X}$-ray of the mastoids (Schuller's view) was taken for all. They were classified as the mastoid being pneumatized or sclerosed;

Table 1: Age distribution

\begin{tabular}{lr}
\hline Age (years) & $n(\%)$ \\
\hline $1-10$ & $9(18)$ \\
$11-20$ & $23(46)$ \\
$21-30$ & $8(16)$ \\
$31-40$ & $8(16)$ \\
$>41$ & $2(4)$ \\
\hline
\end{tabular}

Table 2: Symptom distribution

\begin{tabular}{lc}
\hline Symptom & $n(\%)$ \\
\hline Otorrhea & $50(100)$ \\
Hearing loss & $43(86)$ \\
Otalgia & $1(2)$ \\
Fever & $8(16)$ \\
Giddiness & $1(2)$ \\
Vomiting & $7(14)$ \\
Headache & $7(14)$ \\
\hline
\end{tabular}

Table 3: Clinical signs distribution

\begin{tabular}{lc}
\hline Clinical sign & No. of patients (\%) \\
\hline Tympanic membrane perforation & \\
Posterosuperior & $14(28)$ \\
Attic & $12(24)$ \\
Central & $8(16)$ \\
Subtotal & $5(10)$ \\
Marginal & $3(6)$ \\
Tympanic membrane granulations & $13(26)$ \\
Aural polyp & $8(16)$ \\
Postaural swelling & $7(14)$ \\
\hline
\end{tabular}

bilateral sclerosis was seen in 35 (70\%) patients (Fig. 8). A welldefined cavity as a result of previous surgery was seen in three.

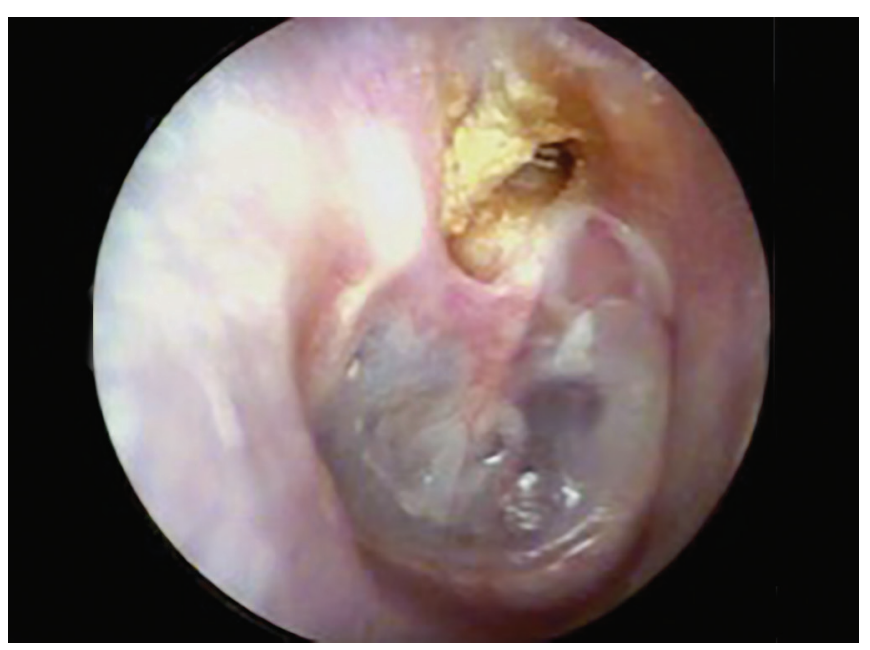

Fig. 4: Attic perforation with cholesteatoma

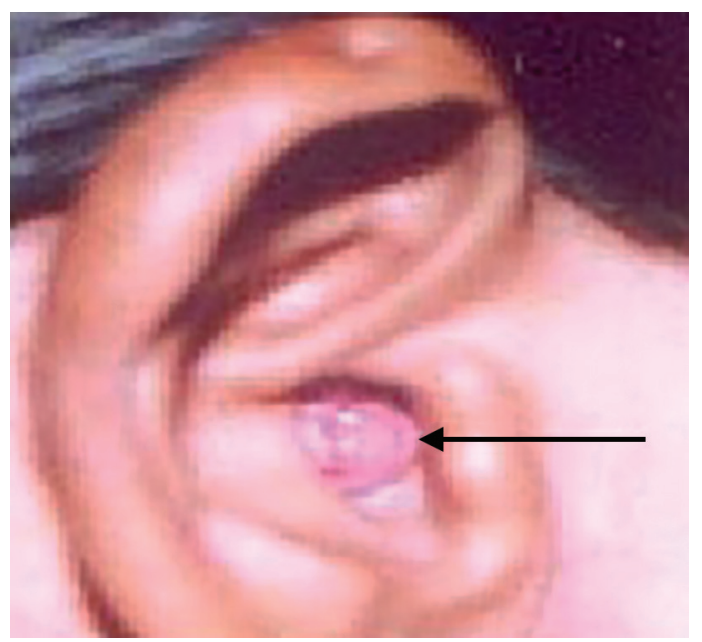

Fig. 5: Aural polyp

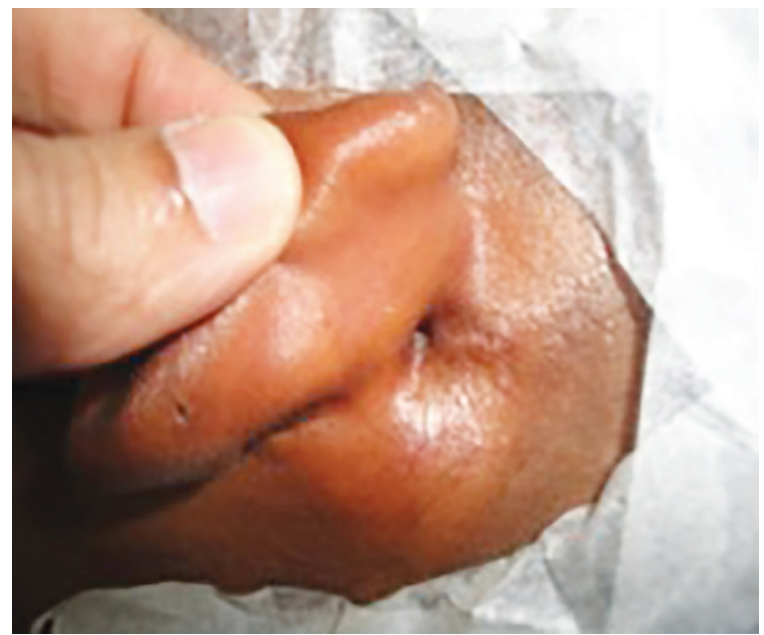

Fig. 6: Postaural fistula 


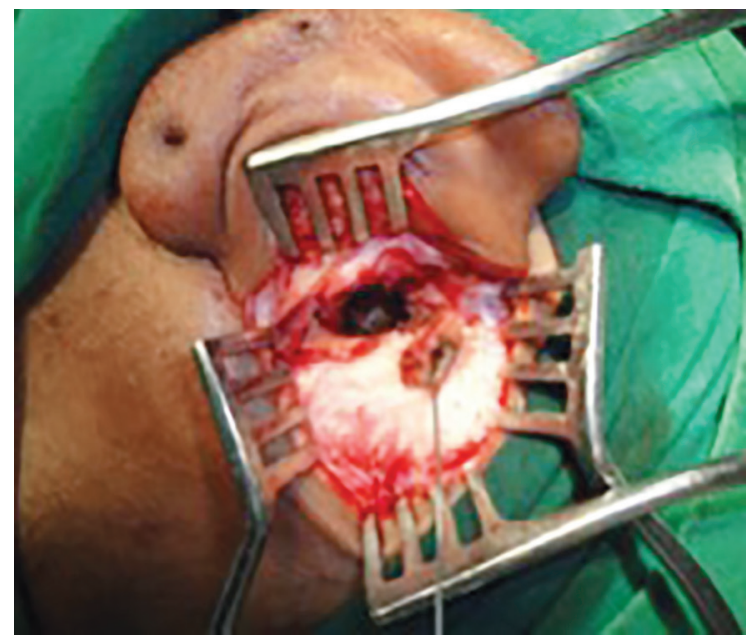

Fig. 7: Postaural fistulous tract (intraoperative)

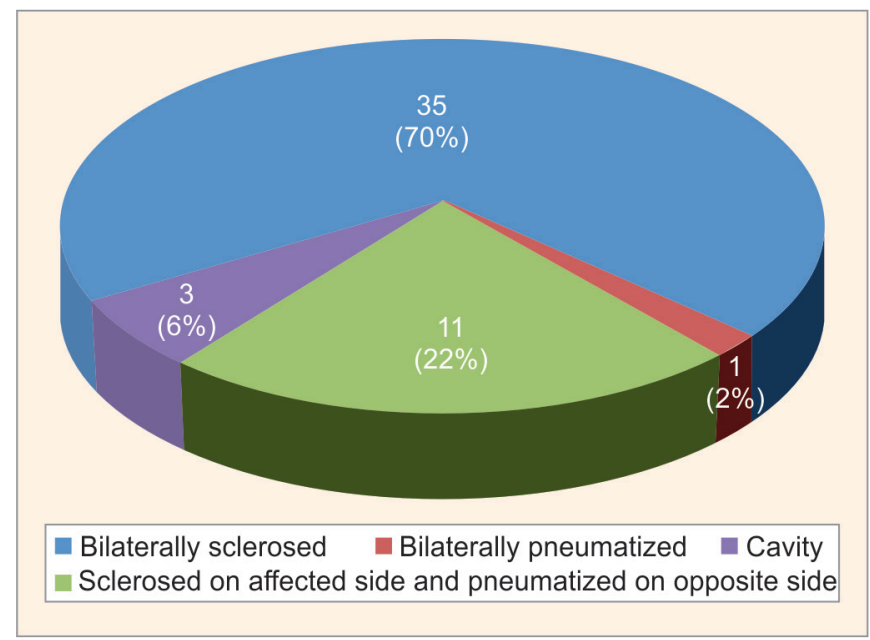

Fig. 8: Radiological findings of mastoid

Of 50 patients, disease complications were noted in 18 (36\%); extracranial ( $n=8,16 \%)$ and intracranial $(n=10,20 \%)$ complications were noted in our study.

The intracranial complications noted were meningitis $(n=03)$, subdural empyema $(n=02)$, cerebellar abscess $(n=02)$, temporal lobe abscess $(n=02)$, and cerebritis $(n=01)$. Among the extracranial complications, mastoid abscess $(n=07)$ and facial nerve palsy $(n=01)$ were reported.

Surgery was performed on the right ear in 26 (52\%) patients and the left ear in 24 (48\%). Surgeries were performed either under local anesthesia (LA) ( $n=32,64 \%)$ or general anesthesia (GA) $(n=18,36 \%)$.

Intraoperatively, the most common location of cholesteatoma was the epitympanum ( $n=31,62 \%)$ followed by mastoid bowl $(13,26 \%)$ (Fig. 9). In the middle ear, the oval window area in eight cases, sinus tympani in seven (14\%) and hypotympanum in three (6\%) were the common sites (Table 4).

The most common site of granulations was the mastoid bowl ( $n=10,20 \%)$ followed by epitympanum ( $n=07,14 \%)$. Six (12\%) had granulations in the oval window area, two (4\%) in the sinodural angle and tegmen area.

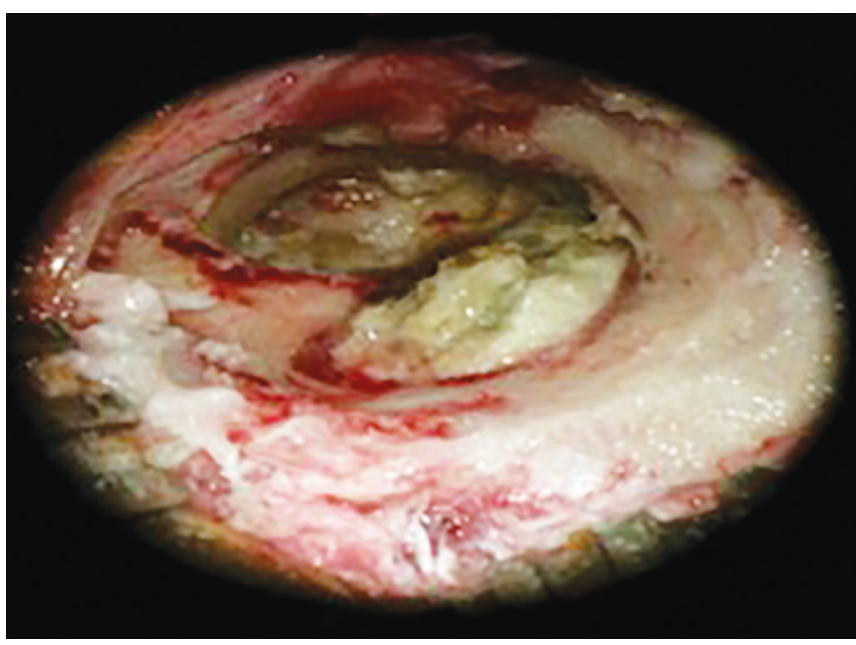

Fig. 9: Cholesteatoma filling the mastoid bowl (intraoperative)

Table 4: Intraoperative location of cholesteatoma

\begin{tabular}{lc}
\hline Intraoperative location of cholesteatoma & $n(\%)$ \\
\hline Mastoid bowl & $13(26)$ \\
Epitympanum & $31(62)$ \\
Hypotympanum & $3(6)$ \\
Oval window & $8(16)$ \\
Sinodural angle & $2(4)$ \\
Tegmen area & $2(4)$ \\
Sinus tympani & $7(14)$ \\
\hline
\end{tabular}

Table 5: Operative findings

\begin{tabular}{lc}
\hline Operative finding & $n(\%)$ \\
\hline Eroded malleus & $24(48)$ \\
Eroded incus & $50(100)$ \\
Eroded stapes & $28(56)$ \\
Facial canal erosion & $5(10)$ \\
Dural plate erosion & $7(14)$ \\
Sinus plate erosion & $2(4)$ \\
Lateral semicircular canal erosion & $2(4)$ \\
\hline
\end{tabular}

All underwent CWDM. The destruction of the incus either part or as a whole was the commonest intraoperative finding noted in all (100\%). Malleus was eroded in 24 (48\%) while stapes superstructure was eroded in 28 (56\%) cases.

Erosion of the lateral semicircular canal bulge was seen in two $(4 \%)$ cases, but the membranous labyrinth was not exposed (Table 5).

Superficial infection of the cavity and transient discharge were seen in 11 (22\%) patients, and all responded to topical and systemic antibiotics. Granulations were noticed in five (10\%) patients, seen at the meatoplasty site or in the cavity healing site. They were noticed during the healing period around 2-6 weeks. All responded to topical antibiotics and steroid ear drops.

Facial nerve involvement after surgery was seen in three patients. The nerve was exposed at the mastoid segment, and the cholesteatoma sac was adherent to the nerve in two of the cases. One had extensive granulations in the mastoid bowl. Facial nerve 
palsy was noted postoperatively and was treated with oral steroids for five days and tapered. There was no recovery at the end of the medical treatment. One patient underwent facial nerve grafting and is recovering whereas the other two patients refused surgery. Two of our patients developed vertigo during the postoperative period and both had erosion of the lateral semicircular canal intraoperatively.

\section{Time Taken for Healing}

These patients were followed up after surgery, and the time for complete healing of the postoperative cavities was noted. Mean \pm SD time taken for healing was 16.96 weeks \pm 2.95 (range $12-28$ weeks). By the end of the fourth month, healing of the postoperative cavities was noted in $33(66 \%)$ patients. By the end of 6 months, epithelialization of the postoperative cavities were noted in 49 (98\%) patients; one patient had persistent ear discharge.

The mean follow-up duration was 7.19 months (range 6.2-12.63 months). Recurrent discharge from the cavity was seen in 11 (22\%) (Fig. 10) whereas granulations and debris were seen in five (10\%) cases each (Table 6).

\section{Discussion}

CSOM, a common cause of preventable deafness often requires mastoid exploration. Mastoid exploration can be classified as "canal wall down" and "canal wall up" procedures depending on the removal or retention of the posterior canal wall. Canal wall down surgeries are the commonly performed surgeries for cholesteatoma especially in the developing countries such as India, because of poor follow-up. Canal wall down techniques include radical and modified radical mastoidectomies.

Many patients with CSOM report late to otolaryngologists, leaving less option other than reconstructive surgery. The mean age of our patients was 21.19 years, comparable to that reported by Garap and Dubey (24 years) ${ }^{9}$; slightly higher mean age (31 years) was reported by Asma et al. ${ }^{10}$ Patients in 11-20 years age-group were affected the most (46\%) in our study, which is in contrast to the observation of Wahid et al. (21-40 years- $45.45 \%) .{ }^{11}$ We noted a male preponderance in our study. All patients underwent modified radical mastoidectomy, and nine underwent concurrent type III tympanoplasty with primary procedure using a septal spur cartilage. Rao and Chandra ${ }^{4}$ reported a male preponderance and

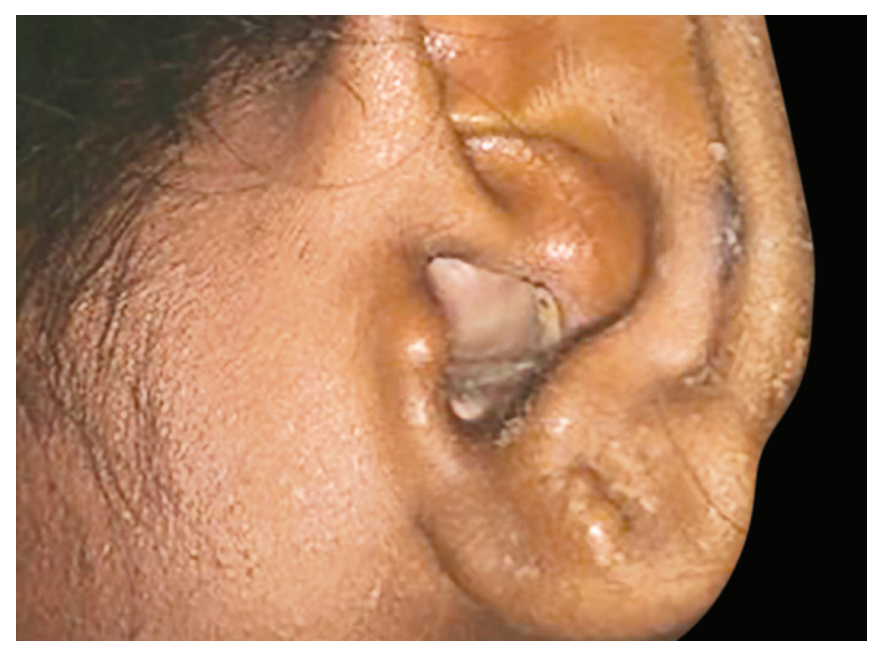

Fig. 10: Discharging cavity during follow-up increased prevalence among 21-30 years of age. Canal wall down surgery was performed in 123 (84.94\%) patients hearing improved in $92.68 \%$ and the procedure failed in five. Kabdwal et al. ${ }^{12}$ too reported that CSOM was most frequent procedure performed for those aged $21-30$ years; ear discharge (100\%) and hearing loss (92.50\%) were the common complaints of their patients. Kulkarni et al. ${ }^{13}$ too reported a similar demographic profile as Kabdwal et al.

All our patients had otorrhea, and hearing loss was seen in $86.0 \%$; otalgia was seen in only one patient. Symptoms of systemic involvement manifested as fever (16\%), vomiting, and headache (14\% each) heralding the complications that are mostly intracranial. Rao and Chandra ${ }^{4}$ reported intermittent foul-smelling discharge from the ear and hearing loss as common symptoms in their patients. Chandrashekharayya et al. ${ }^{14}$ too reported discharge from the ear and earache in all; fever (10), vomiting (06), and headache were the other symptoms.

In our study, bilateral mastoid bone sclerosis was seen in 35 patients (70\%) of whom eight had bilateral disease and 27 had bilateral sclerosis but unilateral disease. It is difficult to infer whether sclerosis predisposes the mastoids to cholesteatoma formation or sclerosis is the result of cholesteatoma. An unusual presentation of sclerosis on the affected side and pneumatized on the opposite side was noted in 11 patients. Cavity was detected radiologically because of previous surgery in $6 \%$.

Vindhya ${ }^{15}$ observed that CSOM was common among those in 5-20 years age-group and showed male preponderance, and hearing loss was complained by all. CWDM surgery was done in $59.37 \%$. Cholesteatoma alone and with granulations were preoperative findings. There was no ear discharge in $>70 \%$ of those who underwent CWDM. Irwan ${ }^{16}$ too reported male preponderance, most common among 16-30 years age group, varying degree of hearing loss, and cholesteatoma (73.8\%). CWDM was performed in $72.6 \%$.

Edelstein et al. ${ }^{17}$ reported otorrhea (73\%), hearing loss (85\%), and otalgia (32\%) as main symptoms with only $0.8 \%$ intracranial complications. These reports show that there has been no change in the presenting complaints since the last three decades though the prevalence has reduced calling for early diagnosis and appropriate management. Complications are associated with poor outcomes, another factor demanding early diagnosis.

We noted perforation of tympanic membrane (84\%), granulations, and polyps (42\%) as major findings. Intraoperatively, all had an eroded incus. Necrosis of the malleus (48\%) and the stapes suprastructure (56\%) were the obvious features. Jamro et al. ${ }^{18}$ noted granulation tissue (62.5\%) and cholesteatoma (37.5\%). Attic, antrum,

Table 6: Complications at follow-up

\begin{tabular}{lc}
\hline Complications at follow-up & $n(\%)$ \\
\hline Recurrent discharge & $11(22)$ \\
Granulations & $5(10)$ \\
Wax & $2(4)$ \\
Vertigo & $2(4)$ \\
Debris & $5(10)$ \\
Persistent discharge & $1(2)$ \\
Cholesteatoma & 0 \\
Facial palsy & $3(6)$ \\
Otomycosis & $2(4)$ \\
\hline
\end{tabular}


and middle ear (37.5\%) and attic and middle ear (37.5\%) were the most affected with necrosis of malleus (62.5\%), incus (52.5\%), and stapes (25\%). Chandrashekharayya et al. ${ }^{14}$ noted cholesteatoma $(10 / 11)$ and attic perforation (9/11) as major findings. Kurien et al. ${ }^{19}$ noted that the malleus was the least affected (67\%) and the incus was the most affected (100\%).

Garap and Dubey ${ }^{9}$ too observed cholesteatoma and granulation tissue with polypoidal mucosa as common intraoperative features. Disease in attic and antrum both followed by only in antrum were noted. Incus was eroded followed by eroded stapes while malleus remained intact in the majority. Meningitis and lateral sinus thrombosis were the common complications. Facial nerve paralysis was reported pre(05) and postoperatively(03). This study reported the death of nine patients, all attributed to intracranial complications.

Otolaryngologists have to identify the complications, particularly intracranial complications that have a poor prognosis, early in the course of the disease to prevent poor outcomes. Meningitis (03), subdural empyema (02), cerebellar abscess (02), temporal lobe abscess (02), and cerebritis (01) were the intracranial complications; a mastoid abscess (07) and facial nerve palsy (01) were the extracranial complications reported in our study. The prevalence of these complications is similar to that reported by Garap and Dubey; ${ }^{9}$ Wahid et al. ${ }^{11}$ noted cholesteatoma in all. The subperiosteal abscess was reported $38.63 \%$, while extradural abscess outnumbered (22.72\%) the intracranial complications.

It is well-documented that CWDM is effective in controlling otorrhea. Paudel ${ }^{3}$ reported no otorrhea in $75 \%$ of patients postoperatively in those who underwent CWDM; however, there was no significant effect of the surgery on hearing as only $16 \%$ had better hearing. Our patients had complete healing (98\%) by 6 months. Recurrent discharge (22\%), granulations (10\%), and debris were the common complications noted during follow-up. Three patients had facial palsy. Longer duration of healing seen in our series may be attributed to the higher rate of infection and not using cavity obliteration procedures. Those patients with smaller cavities and no infection showed better healing, and the cavity was completely epithelialized in 6 months in most of these cases.

Castrillon et al. ${ }^{20}$ reported that CWDM was effective in $95 \%$ of patients, resulting in dry and disease-free ear. Khan et al. ${ }^{21}$ who observed dry ear (92\%) and free from granulation (88\%) postsurgery were in support of Castrillon et al. and recommend CWDM in patients with CSOM requiring surgery. Reports by Vartiainen, ${ }^{22}$ Paparella, and $\mathrm{Kim}^{23}$ indicate the efficacy of CWDM in CSOM. Our study supports these observations.

Flaws of this study are not comparing the procedure with CWUM, small sample size, and not correlating socioeconomic levels. Our follow-up was 6 months, which is shorter as long-term follow-up is required for these patients, which is often difficult, and hence, patients will be lost to follow-up.

In view of the occurrence of cavity problems following CWDM as a primary procedure, we emphasize the need for meticulous surgery (adequately lowered facial ridge, circumferential saucerization, and wide meatoplasty) in every patient as in the majority of cases multiple factors are responsible.

CSOM is a chronic condition that needs to be addressed during the early stages; surgery, though offers relief to a greater extent, has its own disadvantages as well. Long-term follow-up is required, which is often difficult and hence, patients will be lost to follow-up. This makes the patient a frequent visitor to our outpatient department and doctor-dependent. Those who are not under regular follow-up will have persistent canal problems. We emphasize regular follow-up to minimize these postoperative complications and better outcomes.

\section{Conclusion}

CWDM yielded satisfactory outcomes clinically with ample epithelialization of postoperative cavities by the end of 6 months. The commonest cavity problem was recurrent discharge from the cavity followed by granulations and accumulation of debris.

In view of the presence of these cavity problems following CWDM as a primary procedure, there is a need for meticulous surgery (adequately lowered facial ridge, circumferential saucerization, and wide meatoplasty) in every patient. As in the majority of cases, multiple factors are responsible for such problems. Persistence or recurrence of symptoms may require additional procedures.

\section{Clinical Significance}

Complications due to CSOM are avoidable clinical conditions, with surgery a mainstay in the management, due consideration to be given to preoperative assessment, meticulous surgery with regular and adequate follow-up. Postsurgical complications require proper management to avoid further damage. The surgeon should be aware of neurological involvement.

\section{References}

1. Bozan N, Duzenli U, Kundi P, et al. Meatal obstruction following canal wall down mastoidectomy. J Pak Med Assoc 2017;67(9):1450-1451. PMID: 28924294.

2. Roden D, Honrubia VF, Wiet R. Outcome of residual cholesteatoma and hearing in mastoid surgery. J Otolaryngol 1996;25(3):178-181. PMID: 8783083.

3. Paudel DR. Chronic suppurative otitis media atticoantral-type undergone canal wall down mastoidectomy in a peripheral government hospital of Nepal. JNMA J Nepal Med Assoc 2013;52(192):596-599. PMID: 25327234.

4. Rao SM, Chandra PR. A comparative study of canal wall up and canal wall down procedures in the management of atticoantral disease. J Evid Based Med Healthc 2017;4(88):5155-5158. DOI: 10.18410/ jebmh/2017/1029.

5. PalvaT,Hallstrom O.Bacteriology of chronicotitis media.Arch Otolaryng 1992;82(4):359-364. DOI: 10.1001/archotol.1965.00760010361005.

6. Wormald PJ, Nilssen EL. Do the complications of mastoid surgery differ from those of the disease? Clin Otolaryngol Allied Sci. 1997 Aug;22(4):355-357. DOI: 10.1046/j.1365-2273.1997.00026.x.

7. Gyo K, Hirata Y, Yanagihara N. Changes in bacterial flora in the tympanic cavity following tympanoplasty Otorhino Clinic 1994;86:579-582. J-GLOBAL ID:201002118130100612 Reference number:10A1432883

8. Bowdler DA, Walsh RM. The use of Davis pinch grafts to promote epithelialization in a post- mastoidectomy cavity. Rev Laryngol Otol Rhinol (Bord) 1995;116(1):65-68. PMID: 7644851.

9. Garap JP, Dubey SP. Canal-down mastoidectomy: experience in 81 cases. Otol Neurotol 2001;22(4):451-456. DOI: 10.1097/00129492200107000-00006.

10. Asma A, Shaharudin MH, MuhdAlmyzan A, et al. Outcome of canal wall down mastoidectomy: experience in sixty three cases. Med J Malaysia 2013;68(3):217-221. PMID: 23749009.

11. Wahid FI, Khan A, Khan IA. Complications of chronic suppurative otitis media: challenge for a developing country. Kulak Burun Bogaz Ihtis Derg 2014;24(5):265-270. DOI: 10.5606/kbbihtisas.2014.14477. 
12. Kabdwal N, Varshney S, Bist SS, et al. Pre and post operative evaluation of hearing in chronic suppurative otitis media. Indian J Otol 2013;19(4):164-168. DOI: 10.4103/0971-7749.124505.

13. Kulkarni RD, Dharmadhikari CA., Kulkarni VA., et al. Bacteriological study of Chronic Otitis media, Indian Journal of Otolaryngology and Head and Neck Surgery 1993:2(2);110-112.

14. Chandrashekharayya SH, Kavitha MM, Handi P, et al. The management of otogenic lateral sinus thrombosis - a 6 year experience at a tertiary care hospital in north karnataka, INDIA. J Clin Diagn Res 2012;6(7):1272-1275. Available from: http://www.jcdr.net/ back_issues.asp?issn $=0973-709 \times$ \&year $=2012 \&$ month $=$ Septembe r\&volume $=6 \&$ issue $=7 \&$ page $=1272-1275 \& i d=2476$. ID: JCDR/2012/ 4783:2476

15. Vidhya M. A dissertation on comparison of the results of outcome of canal wall up mastoidectomy and canal wall down mastoidectomy for chronic suppurative otitis media. Available from: http:// repository-tnmgrmu.ac.in/id/eprint/1234 [Accessed on November 22, 2017].

16. Irwan AG. Epidemiology, preoperative evaluations and surgical findings in CSOM. Available from: http://eprints.unsri.ac.id/857/1/ Epidemiology_n_surgical_finding_CSOM.pdf [Accessed on November 22, 2017].
17. Edelstein PR, Parisier SC, Ahuja GS, et al. Cholesteatoma in the pediatric age group. Ann Otol Rhino Laryngol 1988;97(1):23-29. DOI: 10.1177/000348948809700105.

18. Jamro BU, Magsi PB, Sangi HA. Intraoperative findings during canal wall down mastoidectomy in chronic suppurative otitis media (CSOM) at Tertiary Care Hospital Sukkur, Pakistan. RMJ 2013;38(2):173-176.

19. Kurien $M$, Job A, Mathew J, et al. Otogenic intracranial abscess: concurrent craniotomy and mastoidectomy--changing trends in a developing country. Arch Otolaryngol Head Neck Surg 1998;124(12):1353-1356. DOI: 10.1001/archotol.124.12.1353.

20. Castrillion R, Kos I, Montandon P, et al. Long-term results of canal wall down mastoidectomy: Schweiz Med Wochenschr 2000;125(Suppl.):58S-65S. PMID: 11141942.

21. Khan AA,Manzoor T, Shah AA, et al. Evaluation of mastoid cavities after canal wall down mastoidectomy. PAFMJ 2009;59. Available from: http://www.pafmj.org/showdetails.php?id=263\&t=0 [Accessed on November 22, 2017].

22. Vartiainen E. Ten-year results of canal wall down mastoidectomy for acquired cholesteatoma: AurisNasus Larynx 2001;27(3):227-229. DOI: 10.1016/s0385-8146(99)00071-1.

23. Paparella MM, Kim CS. Mastoidectomy update. Laryngoscope 1977;87(12):1977-1988. DOI: 10.1288/00005537-197712000-00001. 